\title{
CLINICAL PATTERN AND OUTCOME OF ORGANOPHOSPHORUS COMPOUND POISONING
}

\author{
Ranjith Kumar G. K1, Nagabhushana $S^{2}$, Ranganatha $M^{3}$, Virupakshappa ${ }^{4}$
}

1 Junior Resident, Department of General Medicine, Shimoga Institute of Medical Sciences, Shimoga.

${ }^{2}$ Assistant Professor, Department of General Medicine, Shimoga Institute of Medical Sciences, Shimoga.

${ }^{3}$ Assistant Professor, Department of General Medicine, Shimoga Institute of Medical Sciences, Shimoga.

${ }^{4}$ Professor and HOD, Department of General Medicine, Shimoga Institute of Medical Sciences, Shimoga.

\section{ABSTRACT}

\section{BACKGROUND}

Organophosphate insecticides/pesticides are used widely throughout the world. The organophosphorus poisoning is a very serious condition that needs rapid treatment. Emergent and appropriate management is always desirable to prevent the serious complications and high mortality. In this study, we determine the clinical presentation and outcome of organophosphorus poisoning in our institute.

\section{MATERIAL AND METHODS}

This study carried out in Medicine Department, SIMS, Shimoga, from January 1st, 2016 to April 20th 2016. A total of 100 cases of OP poisoning were studied. We included all patients of organophosphate poisoning presented either with signs of muscarinic involvement or signs of nicotinic involvement. Outcome measured according to W.H.O. classification of severity.

\section{RESULT}

Out of a total 100 patients of organophosphate poisoning were admitted, among these $44 \%$ were males and $56 \%$ females. Average age was $28.9 \pm 8.8$ years. Nausea and vomiting was the most common clinical feature found in $93 \%$ of the patients followe $d$ by salivation seen in $91 \%$ and Miosis in $87 \%$. According to W.H.O. Classification for Severity of Organophosphate poisoning. Mild $46 \%, 37 \%$ cases were moderate and $17 \%$ were severe. Overall mortality rate was $19 \%$.

\section{CONCLUSION}

Present study shows the importance of WHO staging of severity of organophosphorus compound poisoning as mortality increases with severity. Study also showed that delayed arrival, lack of ICU facility and lack of preliminary management at the early stage are the causes of increased mortality in OP compound poisoning. OP compound poisoning needs rapid diagnosis, early and effective treatment to decrease the severity and mortality. These finding shows need for improvement in primary health care facility to decrease morbidity and mortality.

\section{KEYWORDS}

Organophosphorus Compounds, Young Adults, WHO Staging, Primary Health Care.

HOW TO CITE THIS ARTICLE: Kumar RGK, Nagabhushana S, Ranganatha M, et al. Clinical pattern and outcome of organophosphorus compound poisoning. J. Evolution Med. Dent. Sci. 2016;5(47):3030-3033, DOI: 10.14260/jemds/2016/705

\section{INTRODUCTION}

Organophosphate insecticides/pesticides are used widely throughout the world. ${ }^{1}$ Organophosphates from occupational, accidental and intentional exposures are a global health problem, especially in developing countries.

According to WHO, two million people attempt suicide and one million accidental poisoning cases occur each year worldwide.2,3 Organophosphates are the most common mode of poisoning in Asia, being both widespread and resulting in high mortality rate. ${ }^{1,4}$ In several areas, some pesticides have become the trendiest method of suicide, gaining unsavoury reputation among health care personnel and community. ${ }^{4}$

Financial or Other, Competing Interest: None.

Submission 21-04-2016, Peer Review 19-05-2016,

Acceptance 26-05-2016, Published 13-06-2016.

Corresponding Author:

Dr. Ranjith Kumar G. K,

Near GK school,

Jenukalleshwari Krupa,

Ashok Nagar 2nd Cross,

Shimoga-577201.

E-mail: ranjithkumargk@gmail.com

DOI: $10.14260 /$ jemds/2016/705
They are chemical agents used widely throughout the world, especially in agriculture and also a nerve agent in war fares. ${ }^{5}$ The exact prevalence of organophosphate poisoning is unknown in India, as many cases are not informed due to religious, social or cultural reasons.

However, reported incidence of Deliberate Self-Poisoning (DSP) in India is about 5-6 per 100,000 in men and women. Benzodiazepines and organophosphate compounds are commonly used for DSP. 6

The mode of exposure to organophosphates varies including dermal, gastrointestinal and inhalational routes. Symptoms are muscle weakness, muscle fasciculation, cramps, twitching and even sometimes the patient may need ventilatory support due to weakness of respiratory muscles. (Acute cholinergic crisis).7,8,9 Intermediate syndrome and organophosphorus induced delayed neuropathy (COPIND). ${ }^{10}$ are other common complication. The organophosphorus poisoning is a very serious condition that needs rapid treatment. Emergent and appropriate management is always desirable to prevent the serious complications and high mortality.

In this study, we determine the clinical presentation and outcome of organophosphorus poisoning. 


\section{METHODOLOGY}

Study is conducted on 100 consecutive patients admitted in various medical wards of the McGann Hospital attached to Shimoga Institute of Medical Sciences, Shimoga. From January 1st, 2016 to April 20th, 2016, we included all patients of organophosphate poisoning presented either with signs of muscarinic involvement or signs of nicotinic involvement; cases presented with combined signs of both muscarinic and nicotinic involvement were also included. However, we excluded those patients in whom organophosphorus poisoning was doubtful and patients who were intoxicated with organophosphorus mimickers, for example nicotine poisoning, opioid poisoning, mushroom poisoning, gastroenteritis or patients who were diagnosed or suspected of having CNS disease such as parkinsonism and myasthenia. Outcome measured according to W.H.O. classification of severity.

\section{WHO Classification for Severity Signs/Symptoms}

\begin{tabular}{|c|c|c|}
\hline Mild & Moderate & Severe \\
\hline Anorexia, & & Diarrhoea, Pinpoint \\
Headache, & Nausea, & pupils and non- \\
Dizziness, & Salivation, & reactive \\
Weakness, & Lacrimation, & pupils, Respiratory \\
Anxiety, & Abdominal & difficulty, \\
Tremors of the & Cramp, & Pulmonary \\
tongue and & Vomiting, & oedema, Cyanosis, \\
the eye lids, & Sweating, Slow & Loss of sphincter \\
Miosis, & pulse, Muscular & control, \\
Impairment of & tremors & Convulsions, Heart \\
vision & & block, Coma \\
\hline
\end{tabular}

\section{Data Analysis}

After taking informed consent, exact mode of poisoning was ascertained and detailed clinical examination was done. Statistical analysis was performed. Descriptive statistics (Frequency and percentage) were computed for categorical variable like sex, age group, clinical presentation and outcome.

\section{RESULTS}

100 patients of organophosphate poisoning were admitted. Among these, $44 \%$ were males and $56 \%$ females.

\begin{tabular}{|c|c|c|}
\hline Sex & No. of Patients & Percentage \\
\hline Male & 44 & 44 \\
\hline Female & 56 & 56 \\
\hline \multicolumn{2}{|c|}{ Table 1: Showing Sex Distribution } \\
\hline
\end{tabular}

The male-to-female ratio is $1: 1.12$.

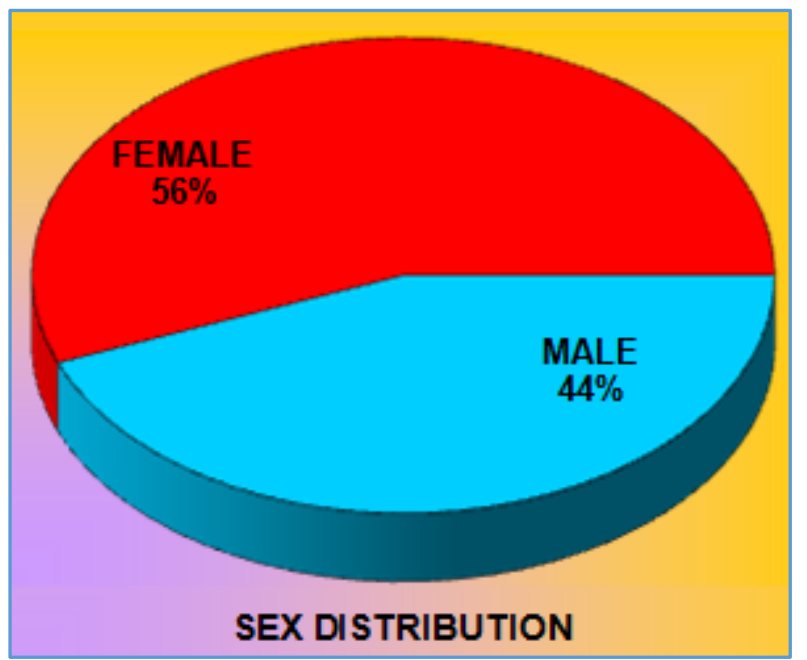

Chart 1: Showing Sex Distribution

\begin{tabular}{|c|c|c|}
\hline Age Group & No. of Patients & Percentage \\
\hline $11-20$ & 10 & 10 \\
\hline $21-30$ & 33 & 33 \\
\hline $31-40$ & 27 & 27 \\
\hline $41-50$ & 15 & 15 \\
\hline $51-60$ & 12 & 12 \\
\hline Above 60 & 3 & 3 \\
\hline \multicolumn{2}{|c|}{ Table 2: Showing Age Distribution } \\
\hline
\end{tabular}

Average age was $28.9 \pm 8.8$ years. The majority of these patients belong to the age group of 21-30 years. The highest number of cases (33\%) was from the age group of 21 to 30 years.

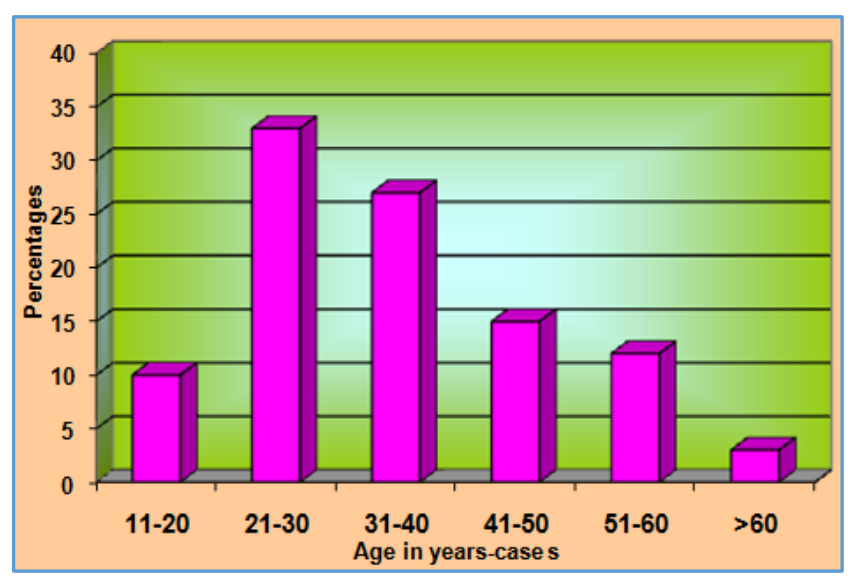

Chart 2: Showing Age Distribution

Various clinical presentation of acute organophosphate poisoning are presented (Table 3 ).

\begin{tabular}{|c|c|c|}
\hline Clinical Features & No. of Patients & Percentage \\
\hline \multicolumn{3}{|l|}{ Pulse Rate } \\
\hline $45-65$ & 23 & 23 \\
\hline $66-75$ & 50 & 50 \\
\hline$>75$ & 27 & 27 \\
\hline \multicolumn{3}{|l|}{ Cardiac Manifestation } \\
\hline Qt Interval Normal & 78 & 78 \\
\hline Qt Interval Prolonged & 28 & 28 \\
\hline Miosis & 87 & 87 \\
\hline Bronchospasm & 72 & 72 \\
\hline Anxiety and Restlessness & 88 & 88 \\
\hline Fatigue & 50 & 50 \\
\hline Salivation & 91 & 91 \\
\hline Lacrimation & 44 & 44 \\
\hline Nausea and vomiting & 93 & 93 \\
\hline Sweating & 55 & 55 \\
\hline Fits & 11 & 11 \\
\hline Muscle weakness & 19 & 19 \\
\hline Cranial palsies & 4 & 4 \\
\hline Respiratory distress & 26 & 26 \\
\hline Coma & 7 & 7 \\
\hline Intermediate syndrome & 9 & 9 \\
\hline \multicolumn{3}{|c|}{ Table 3: Showing Clinical Presentations } \\
\hline
\end{tabular}

Nausea and vomiting was the most common clinical feature found in $93 \%$ of the patients followed by Salivation seen in $91 \%$ and Miosis in $87 \%$. 


\begin{tabular}{|c|c|c|c|}
\hline $\begin{array}{c}\text { W.H.0 } \\
\text { Grading }\end{array}$ & Total (\%) & Discharged & $\begin{array}{c}\text { Expired } \\
\text { (\% of Death) }\end{array}$ \\
\hline Mild & $46(46)$ & 44 & $2(4)$ \\
\hline Moderate & $37(37)$ & 28 & $9(24)$ \\
\hline Severe & $17(17)$ & 9 & $8(53)$ \\
\hline Total & $\mathbf{1 0 0 ( 1 0 0 )}$ & $\mathbf{8 1}$ & $\mathbf{1 9}(\mathbf{1 9 )})$ \\
\hline \multicolumn{3}{|c|}{ Table 4: Outcome of Patients According } \\
to W.H.O Classification (n=100)
\end{tabular}

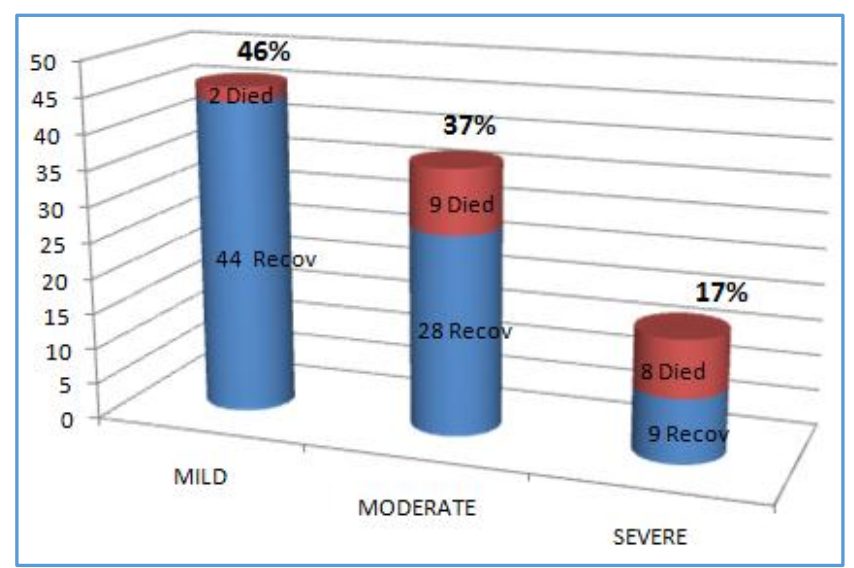

Chart 3: Outcome of Patients According to W.H.O Classification

According to W.H.O. Classification for Severity of Organophosphate poisoning. Mild 46\%,37\% cases were moderate and $17 \%$ were severe. Among those with severe grade, $66 \%$ patients belonged to the age group of $16-30$ years. Before presenting to tertiary care facility, only $7 \%$ of all patients received specific emergency treatment at primary health care facility, $68 \%$ patients received non-specific emergency treatment, while $25 \%$ did not receive any treatment. Among those who received specific treatment, 7 patients recovered and 2 patients expired. Among those who received emergency but non-specific treatment, 58 patients survived and 5 expired. For those who did not receive any treatment, 8 patients expired and only 17 recovered.

Overall mortality rate was $19 \%$. Out of $19 \%$ patients, 9 (47\%) were males and 10 (53\%) were females. According to W.H.O classification for severity, among 17 patients who presented with severe symptoms 9 patients were discharged to home and 8 expired. For those 37 patients with moderate symptoms 28 recovered, while 9 patients expired. Those with mild symptoms 44 recovered, 2 died.

\section{DISCUSSION}

Organophosphorus compounds are used globally for pest control over 100 years. These are common agents for suicide and accidental poisoning due to its easy availability. ${ }^{10}$ In agricultural countries like India, toxicity of pesticide as well as lack of medical services causing high increase morbidity and mortality.

The data derived from the study clearly showed that organophosphorus poisoning was common in females (56 were females and 44 were males). This female preponderance is sharp contrast to the study done by many international studies. ${ }^{10,11,12}$ However, it is in correlation with study done by Paudyl BP.13 who showed that females attempted suicides more than males. Only common in this locality, but also seen in some others parts.
In this study, suicidal mode of poisoning was common. Majority of the cases were young people from the age group 21-40 years about $60 \%$; this is comparable to other studies as done by Singh $\mathrm{D}$ et al, ${ }^{14}$ in which maximum number of patients were between 15-35 years of age. This finding is also supported by study of Singh S et al 15 and Singh S Wig N et al. 16

Most frequent signs noted in the study were nausea and vomiting in $93 \%$ followed by Salivation $91 \%$ and Miosis $87 \%$, other frequent clinical features noted in this study are also comparable with other studies likes Tahir MH et al ${ }^{11}$ and Karki P et al. ${ }^{17}$

In this study, it also became evident that out of 19 patients who expired 8 patients received no therapy before coming to the hospital and arrived late, also supported by study done by Suliman MI et al. ${ }^{1}$ Mortality rate was $20 \%$ similar to study done by Numidasa UA et al.18 However, $5 \%$ mortality higher than the study by Paudyal BP. 13 was observed in our study which may be due to lack of ICU facilities, late arrival, not receiving any treatment at periphery before arrival to the hospital, poverty and less education.

\section{CONCLUSION}

Present study shows the importance of WHO staging of severity of Organophosphorus compound poisoning, as the mortality increases with severity. Study also showed that delayed arrival, lack of ICU facility and lack of preliminary management at the early stage are the causes of increased mortality in OP compound poisoning. OP compound poisoning needs rapid diagnosis, early and effective treatment to decrease the severity and mortality. These findings show the need for improvement in primary health care facility to decrease morbidity and mortality of Organophosphorus compound poisoning.

\section{REFERENCES}

1. Suliman MI, Jibran R, Rai M. The analysis of organophosphorus poisoning cases treated at bahawalpur victoria hospital, Bahawalpur in 2000-2003. Pak J med Sci 2006;22(3):244-49.

2. Eddleston M, Buckley NA, Eyer P, et al. Management of acute organphosphorus pesticide, poisoning. Lancet 2008;371(9612):597-607.

3. Aardewa H, Meerteng JH, Lightemberg JJ. Organophosphorus pesticide poisoning: case and developments. Neth J Med 2008;66(4):149-53.

4. Eddelston M, Sherrif MH, Hawton K. Deliberate self-harm in Sri Lankan overlooked tragedy in the developing world. BMJ 1998;317:133-5.

5. Joshi S, Biswas B, Malla G. Management of Organophosphorus poisoning 2005. Available from URL http:// ww.nda.ox.ac.uic/wfsa/html/u1913_0.1htm.

6. Gupta SK, Kumar S, Sheikh MI. Study of organophosphorus poisoning in Surat, India. JIAFM 2006;28(3):83-7.

7. Brid S, Gaspari RJ, Dickson EW. Early death due to sever organophosphorus poisoning in the centrally mediated process. Acard Emerg Med 2003;10(4):295-8.

8. Augan D, Doganay Z, Altintop L, et al. Serum acetyl cholinesterase and prognosis of acute organophosphorus poisoning. J Taxical Clin Toxicol 2002;40(7):903-10. 
9. Eddleston M, Philips MR. Self-Poisoning with pesticide. BMJ 2004;328(7430):42-4.

10. Hussain AM, Sultan T. Organophosphate insecticide poisoning: management in surgical intensive care unit. J coll physician surg Pak 2000;15:100-2.

11. Tahir MH, Raja JI, Haq IU. Acute organophosphorus poisoning- an experience. Pak Armed Forces Med J 2006;56:150-56.

12. Karam RA, Rashid I, Ashiq M. Acute poisoning due to commercial pesticide in Multan. Pak J Med Sci 2002;18:227-31.

13. Paudyal BP. Poisoning: pattern and profile of admitted cases in a hospital in central Nepal. J Nepal Med Assoc 2003;44:92-6.

14. Singh D, Tyagi S, Jit I. Changing trends in acute poisoning in Chandigarh zone: a 25 years autopsy experience from a tertiary care hospital in northern India. Am J Forens Med Pathol 1999;20(2):203-10.
15. Singh S, Sharma BK, Wahi PL, et al. Spectrum of acute poisoning in adults (10 year experience). J Assoc Physic India 1984;32(7):561-3.

16. Singh S, Wig N, Chaudhary D, et al. Changing pattern of acute poisoning in adults: experience of a large northwest Indian hospital (1970-1989). J Assoc Physic India 1997;45:194-7.

17. Karki P, Ansari JA, Bhandary S, et al. Cardiac and electrocardiographical manifestation of acute organophosphate poisoning. Singaporen Med J 2004;45(8):385-9.

18. Numidasa UA, Gawarammana IB, Kularatne SA, et al. Survival pattern in patients with acute organophosphate poisoning receiving intensive care. J Toxicol Clin Toxicol 2004;42(4):343-7. 